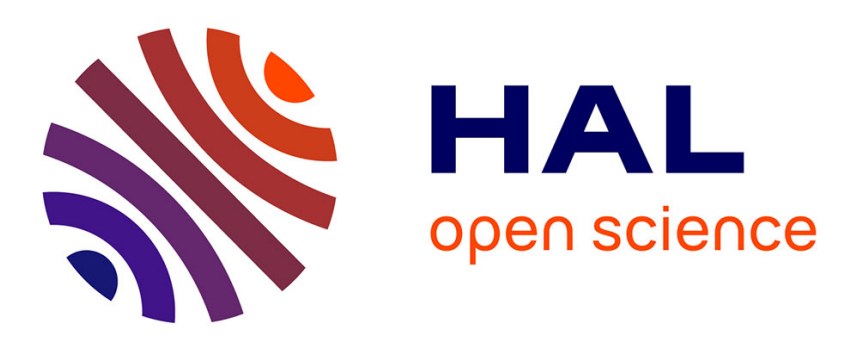

\title{
On the impact behaviour of Ti-alloy superplastically deformed and diffusion bonded sandwich panels
}

\author{
C. Ruiz, M. Rollins, G. Hillsdon
}

\section{To cite this version:}

C. Ruiz, M. Rollins, G. Hillsdon. On the impact behaviour of Ti-alloy superplastically deformed and diffusion bonded sandwich panels. Journal de Physique IV Proceedings, 1994, 04 (C8), pp.C8-583C8-588. 10.1051/.jp4:1994891 . jpa-00253452

\section{HAL Id: jpa-00253452 https://hal.science/jpa-00253452}

Submitted on 1 Jan 1994

HAL is a multi-disciplinary open access archive for the deposit and dissemination of scientific research documents, whether they are published or not. The documents may come from teaching and research institutions in France or abroad, or from public or private research centers.
L'archive ouverte pluridisciplinaire HAL, est destinée au dépôt et à la diffusion de documents scientifiques de niveau recherche, publiés ou non, émanant des établissements d'enseignement et de recherche français ou étrangers, des laboratoires publics ou privés. 


\title{
On the impact behaviour of Ti-alloy superplastically deformed and diffusion bonded sandwich panels
}

C. Ruiz, M.A. Rollins $(1)$ and G.K. Hillsdon

Oxford University, Technology Centre for Solid Mechanics, Department of Engineering Science, Parks Road, Oxford OXI 3 PJ, U.K.

\begin{abstract}
Ti-alloy panels consisting of a honeycomb or a corrugated sheet sandwiched between two skins are widely used in aerospace where they may be subjected to impulsive loading. 'The tests described aim to reproduce the parameters governing the impact behaviour of such panels. Emphasis is placed on three types of tests: shear, compression, and bending. The apparatus and instrumentation are described as well as the significance of some of the experimental results.
\end{abstract}

\section{Introduction}

Ti-alloy panels consisting of a honeycomb or a corrugated sheet sandwiched between two skins - Fig. 1-, used in airframes and aeroengines, must be designed to withstand the impact of small hard objects such as pebbles and of birds. Impact properties often determine the choice of design parameters, i.e., the thickness of the front and back sheet, the thickness and pitch of the corrugation or honeycomb and the overall thickness of the panel. It would be too costly and time consuming to find the optimum combination by full scale testing alone. Small test coupons, loaded under appropriate conditions and supported by numerical analysis is the preferred route. This report describes the tests used to design for bird impact.

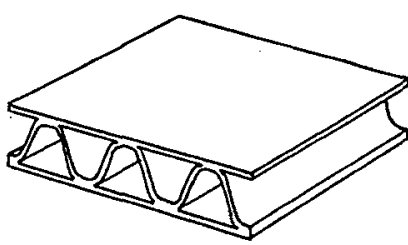

(a)

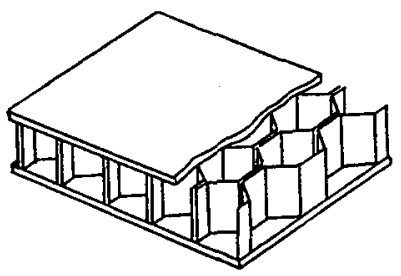

(b)

Fig.1 Typical sandwich panels, (a) honey comb, (b) corrugated core

\section{Design of tests}

The guidelines that exist for static testing of sandwich panels $[1,2]$ are not applicable to impact loading. To simulate bird impact, a fast load rise time and a high contact stress are required. Typically, at an impact velocity of $300 \mathrm{~m} \mathrm{~s}^{-1}$, the duration will be less than $0.1 \mathrm{~ms}$ and the peak shock pressure will be of the order of $600 \mathrm{MPa}$ [3-6]: Two approaches may be followed to fix the impact velocity in the test:

(1) Now with Royal Dutch Shell 
(i) the strain rates in the specimens must be the same as in the actual bird impact.

(ii) the peak pressure must be the same in both cases.

The value of the stagnation or steady state pressure that is responsible for the plastic deformation of the target can be estimated by,

$$
p=\rho v_{i}^{2}
$$

where $\rho$ is the bird density and $v_{i}$ the impact velocity. Since $\rho$ is about $1000 \mathrm{~kg} \mathrm{~m}^{-3}$ and $v_{i}$ is about $400 \mathrm{~m} \mathrm{~s}^{-1}$, then $\rho=160 \mathrm{MPa}$ is an estimate of the magnitude of the transverse stress needed in the tests. The magnitude of the stress pulse created in a stationary bar by the impact of a second bar travelling at velocity $v$ is,

$$
\sigma=\frac{1}{2} \rho^{\prime} C v
$$

where $\rho^{\prime}$ is the density of the bar material and $c$ is the longitudinal wave speed.

For equivalence between the steady state pressure and the compressive stress in the bar,

$$
v=\frac{2 \rho v_{1}^{2}}{\rho^{\prime} c}
$$

In the Hopkinson bar apparatus in which these tests were carried out, $\rho^{\prime}=78.50 \mathrm{~kg} \mathrm{~m}^{-3}$ and $c=5200 \mathrm{~m} \mathrm{~s}^{-1}$ giving $v=7.84 \mathrm{~m} \mathrm{~s}^{-1}$. As has been mentioned, the peak pressure will be higher that the stagnation pressure, requiring a higher value of the velocity. The maximum velocity in the impact bar, limited by the yield point of the material, is $20 \mathrm{~m} \mathrm{~s}^{-1}$. The tests were conducted at $10 \mathrm{~m} \mathrm{~s}^{-1}$ to simulate the effect of the stagnation pressure and at $20 \mathrm{~m} \mathrm{~s}^{-1}$ to give an estimate of the combined effect of stagnation and shock pressures.

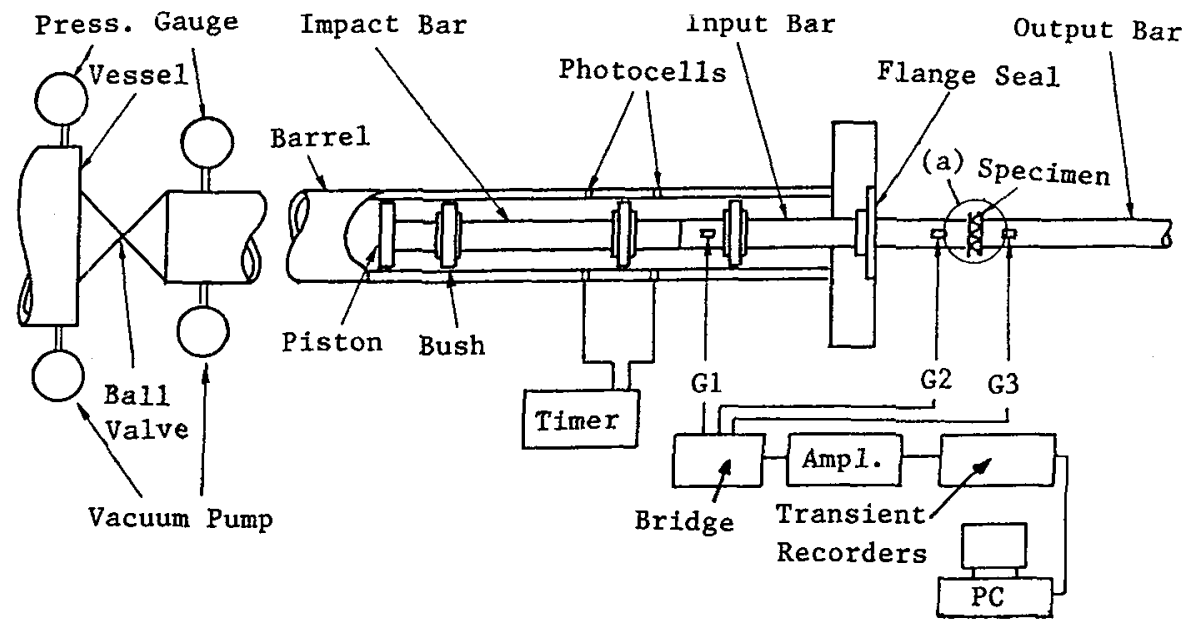

Fig.2 General arrangement of Hopkinson bar apparatus and ancillary instrumentation

Fig. 2 gives a general arrangement of the apparatus and its ancillary instrumentation. Three types of specimens were used for compression, bending and shear testing (Fig. 3). In the compression test the specimen was held between the input and output bars, as indicated in Fig. 2. In the other two tests the specimen rested on the main frame of the testing machine without an output bar. Measurements were then taken only from the input bar.

The impact and input bars were both $1 \mathrm{~m}$ long and $25 \mathrm{~mm}$ in diameter. The output bar was $2 \mathrm{~m}$ long and the same diameter.

The interpretation of the strain gauge signal follows the well known practice for the split Hopkinson bar apparatus [7]. 
(a)

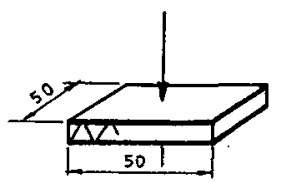

(c) (b)

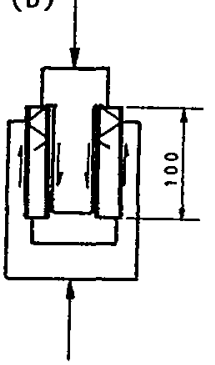

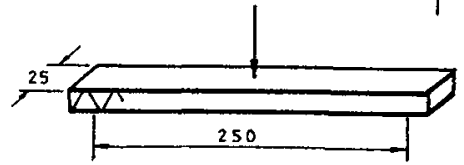

Fig.3 Specimens used, (a) compression, (b) bending, (c) shear

Compression tests

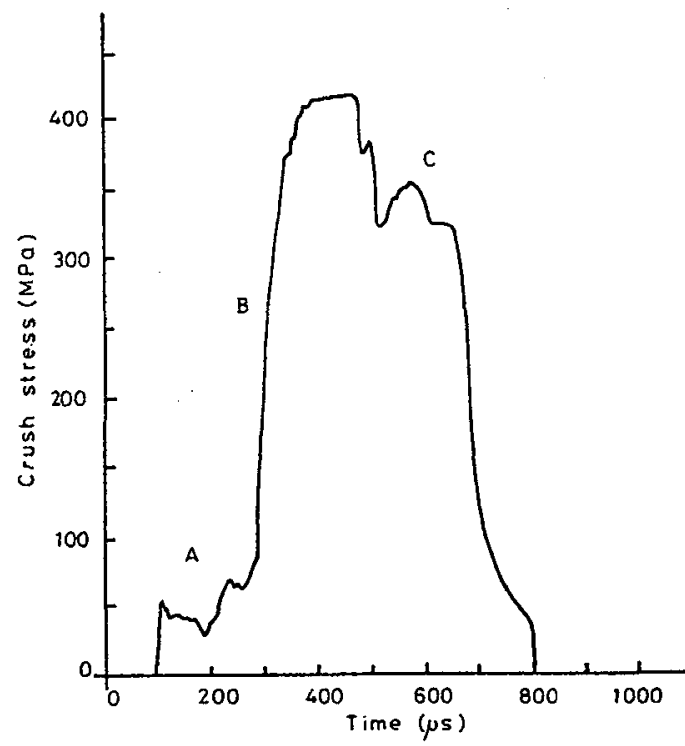

Fig.4 Typical stress against time curve from the strain gauge data

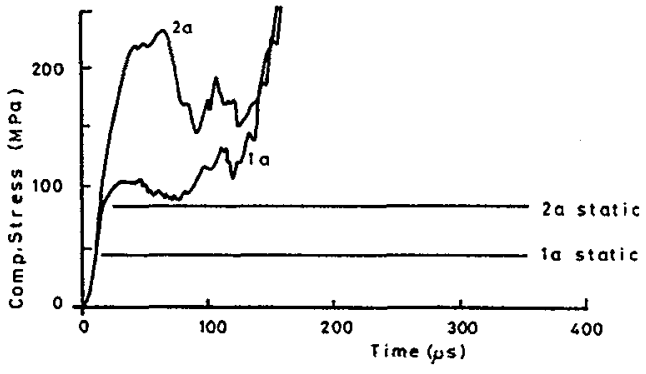

Fig.5 Compression response in deformation region: corrugated core

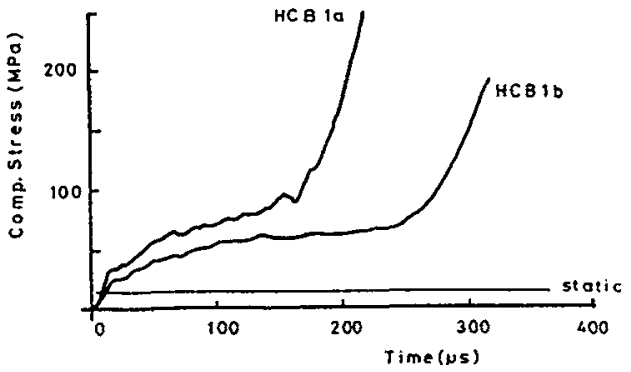

Fig.6 Compression response in deformation region: honeycomb core

A typical plot of contact stress against time from the strain gauge data is shown in Fig. 4. Three main regions are clearly seen: the initial deformation region, the compaction region and the unloading region. The most important is the first, since it provides a measure of the resistance to crushing. This region is shown in more detail in Fig. 5 for corrugated core panels and Fig. 6 for honeycomb core panels. In all cases there is an initial rise followed by yielding of the core and the onset of crushing as the stress reaches its peak value. In Fig. 5, curve 1a corresponds to a core thickness of $0.56 \mathrm{~mm}$ and $2 \mathrm{a}$ to $1.07 \mathrm{~mm}$, otherwise both specimens are identical, with a pitch $5.72 \mathrm{~mm}$. In Fig. 6, the curve 1a corresponds to a 
honeycomb core with a height of $4.17 \mathrm{~mm}$ sandwiched between two $1.5 \mathrm{~mm}$ thick faces and curve $1 \mathrm{~b}$ to a honeycomb core with a height of $6.96 \mathrm{~mm}$ sandwiched between two $0.89 \mathrm{~mm}$ thick faces. Both cores are otherwise identical, with a thickness equal to $0.08 \mathrm{~mm}$ and hexagonal side of $3.18 \mathrm{~mm}$ length. In all cases the static crushing strength is lower that the plateau reached during the dynamic test. Numerical analysis, using $A B A Q U S$, predicts strain rates in the corrugation legs of the order of $10^{4} \mathrm{~s}^{-1}$, as in the actual bird impact incident [8].

The second region, marked B in Fig.4, corresponds to the two faces of the specimen coming together. The third region, marked $\mathrm{C}$, is a fall in stress corresponding to the unloading of the specimen.

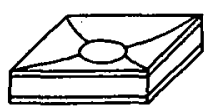

(a)

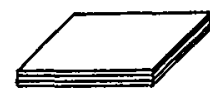

(c)

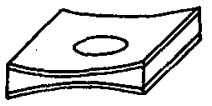

(b)

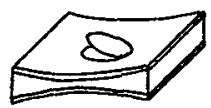

(d).

Fig.7 Permanent deformations of compression specimens

Examination of the specimens after a test gives useful information. In several cases the crushed zone propagated along the direction of the corrugations as shown in Fig. 7(b). This was seen for deep, thin corrugated cores which show a tendency to buckle. In others, it formed a deep indentation with a diameter equal to that of the input bar. This behaviour, shown in Fig. 7(a) was seen in specimens with strong cores. In an extreme case, the whole specimen was squashed, Fig. 7(c). Specimens with thin faces also had a tendency to have a hole punched in the impact face, as illustrated in Fig. 7(d). The honeycomb specimens showed deformations of the type pictures in Fig. 7(c).

\section{Bending tests}

In this test the specimen bends on impact and thus loses contact with the input bar at all but two points. The strain gauge data can then be interpreted in terms of the applied force but it does not give an accurate measure of deflection.
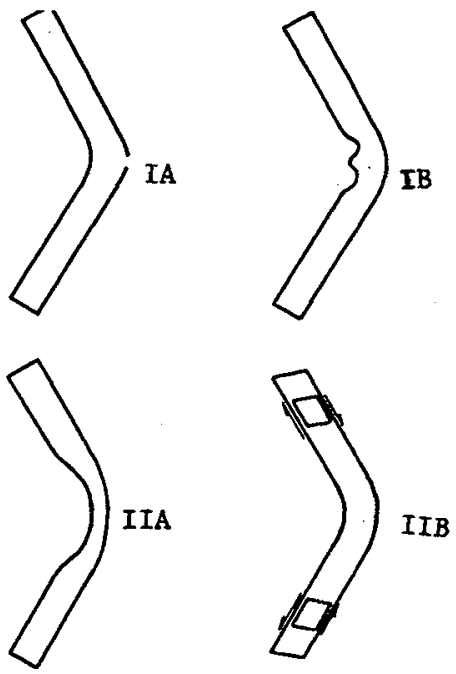

Fig.8 Mode of failure observed in the bending test 
The response of monolithic plates tends to fall into two categories depending on the extent of the deformation. At low impact velocities, the whole plate deforms, either elastically or plastically depending on the kinetic energy of the impactor. Above a certain velocity the deformation or damage is confined to a small region around the point of impact and is governed by the material properties rather than by the structural behaviour of the plate as a whole. Sandwich panels respond in a more complicated manner. Those with a core sufficiently strong to maintain the separation between the two faces develop high tensile strains in the back face and break by tearing (Mode IA, Fig. 8) or, when the front face is relatively thin and the pitch of the corrugated core is large, by crushing of the front face (Mode IB, Fig. 8). The crushing type of failure begins to develop soon after impact, typically within the first $0.8 \mathrm{~ms}$. Tearing only occurs after substantial deflection has taken place, typically after $1.6 \mathrm{~ms}$. At low impact velocities, local tearing or crushing ceases to be the dominant mode of failure. The deformation spreads over a large portion of the beam and can take the form of a gradual reduction of depth (Mode IIA, Fig. 8) or a shear between the two faces and the core (Mode IIB, Fig. 8). In either case, the strains in the front and back faces change as a result of this global deformation and final failure, by tearing or crushing, when it happens, no longer depends on the original geometry. Shear failure occurs following Mode IIB and is particularly prevalent in the case of honeycomb cores.

Failure by tearing of the back face leads to localisation of the post failure deformation. The flexural rigidity becomes negligible at the cross section where the fracture occurs and if load is maintained the deformation will be concentrated in the immediate region of the fracture. In a similar way, crushing is always dominated by one particular corrugation. As the deflection grows the rigidity of the section decreases and the curvature of the panel becomes sharply localised.

Failures which occur by crushing of the core tend to distribute the deformation over the whole impact area. This deformation may propagate in the direction of the corrugations as indicated by post-test examination of the compression test specimens but the amount of bending moment sustained by the panel will not show the sharp decline detected in the previous types of failure and some of the load bearing capacity of the panel will remain.

\section{Shear tests}

These tests highlight the limitations of one-dimensional stress wave theory for the interpretation of Hopkinson bar tests. The loading rig (Fig. 2) gives rise to complex stress wave reflections that result in correspondingly complicated strain gauge signals. The main source of information is then a photographic record, which highlights the localisation of damage. The effect of the impact is to load the faces longitudinally. A large amount of energy is transferred from the moving bar to a relatively small area of specimen. This causes an initial very rapid buckling of the face between the first one or possibly two corrugation bays, generally followed by multiple brittle fractures and disintegration of a localised region of the specimen. The honeycomb specimens were by far the worst performers under shear. The entire core structure was sheared apart in the tests, indicating a considerable weakness compared to the corrugated core specimens.

\section{Discussion and conclusions}

In the compression tests there is considerable resistance to crushing after initial failure of the core structure. The membrane thickness and the line pitch determine the strength. The core membrane thickness also has a predictably strong influence. The honeycomb specimens performed relatively well in this area.

Although in some cases it is difficult to determine a true value for the magnitude of the stress, due to factors such as the face thickness which affects the area of spreading of the contact force, similar specimens can be effectively ranked by these tests. 
It is generally accepted that the most important factors influencing the dynamic crushing are the inertial effects and the high material strain rates in the corrugation legs indicated by the rate of reduction in thickness of the panels. The inertial aspects tend to be of more importance for structures consisting of arrays of thin-walled elements, such as the tubes investigated by Reid [9]. In the case of a single structural element such as the corrugation legs considered here it seems that the strain rate effects dominates.

The strain against time results have shown two levels of behaviour, one consisting of straightforward deformation of the core structure, and a second consisting of the crushing of the folded core membrane. In most cases the velocity of the input bar is not greatly reduced until the second type of behaviour occurs.

The bending tests reveal several modes of failure. Two classes of behaviour have been identified - one associated with the crushing of the core structure and one with the failure of the faces. The crushing type of failure is peculiar to impact loading.

The analysis of the failure modes is very difficult analytically for both static and dynamic loads. However, it has been shown that those modes which result from locally rigid deformation may be approached from a quasistatic viewpoint. The membrane stress at any point in the structures depends not only on the overall geometry of the structure and loading but also on the position relative to the bonds. Between bonds these stresses form a discrete rather than continuous set of values over the structure and any failure criterion must be based on this set of values.

The shear tests do not yield much new information. Nevertheless, the relative weakness of the honeycomb compared to the SPF structures in this area has been highlighted.

\section{References}

1. Standard test methods for flatwise compressive strength of sandwich cores, ASTM Standard C365

2. Standard test for flexure of sandwich constructions, ASTM Standard C393

3. Peterson R.L. and Barber J.P., Bird impact forces in aircraft windshield design, AFFDL-TR-150. 1976

4. Allcock A.W.R. and Collin D.M., The development of a dummy bird for use in bird strike research, National Gas Turbine Establishment, CP-1071, 1968

5. Willbeck J.S., The development of a substitute bird model, Trans. ASME, J.Eng. Power, 4, 1981, 103.

6. Barber J.P., Taylor H.R. and Willbeck J.S., Bird impact forces and pressures on rigid and compliant targets, AFFDL-TR - 77-60, 1978

7. Harding J., Testing techniques at impact rates of strain, Lecture notes, Course on Mech. Prop. of Matls. at High Rates of Strain, Oxford Univ., 6-8 March, 1991

8. Rollins M.A., Impact on panels of sandwich construction, D.Phil. Thesis, Oxford Univ., 1990

9. Reid S.R., Laterally compressed tubes as impact energy absorbers In N. Jones and T. Wierzbicki, ed. Structural Crashworthiness, 1983 